\title{
special news and notes
}

\section{GPS/MET Successfully Launched-Early Data Look Excellent*}

On 3 April 1995 a Pegasus rocket carried a small satellite, MicroLab-1, into a low-earth orbit. Circling the earth every $100 \mathrm{~min}$ at an altitude of approximately $750 \mathrm{~km}$ and an inclination angle of 70 degrees, the satellite carries a radio receiver that is receiving signals from the constellation of 24 GPS (Global Positioning System) satellites. Approximately 500 times each day, as the satellite rises or sets relative to the GPS transmitters, it receives radio signals that are bent (refracted) as they pass through the atmosphere. Knowing precisely where the satellites are (within centimeters) and precisely when the signals are transmitted and received, it is possible to calculate vertical profiles of atmospheric refractivity $\mathrm{N}$, which can then be used in a variety of ways for climate monitoring and research and weather prediction.

The successful launch of MicroLab-1 was a major milestone in the project known as GPS-MET (GPSMeteorology). Under the leadership of Randolph Ware and Mike Exner of UCAR's UNAVCO (University NAVSTAR Consortium) program, GPS-MET is a proofof-concept experiment designed to obtain accurate and high-resolution vertical profiles of temperature and water vapor on a global basis. GPS-MET uses radio occultation, a method used successfully for many years for remote sensing of the atmospheres of the planets Venus, Mars, Jupiter, Saturn, Uranus, and Neptune. Other principal investigators on the GPSMET project include Christian Rocken (UNAVCO), Ben Herman (University of Arizona), Bill Kuo (NCAR), Thomas Meehan (JPL), and Mikhail Gorbunov and Sergei Sokolovskiy (Russian Institute of Atmospheric Physics). GPS-MET is sponsored by the National Science Foundation, NASA, NOAA, FAA, and Orbital Sciences Corporation (OSC), which provided the GPSMET launch. Allen Osborne Associates supported the development of the special GPS-MET receiver.

Theoretical studies and preliminary results from the GPS-MET experiment have shown that accurate profiles of refractivity $\mathrm{N}$ can be obtained using the radio occultation method from an altitude of about $50 \mathrm{~km}$ extending downward close to the surface. Refractivity $\mathrm{N}$ is a function of temperature, pressure, and water vapor. With independent estimates of either temperature or water vapor, it is straightforward to compute the other variable. However, for many uses such as monitoring of global climate change and for numerical weather prediction, it is not necessary to separate out the temperature and moisture effects. Thus, for climate monitoring, global and regional trends of refractivity alone would be an indicator of climate change. For numerical weather prediction, it is possible to adjust the model's forecast through data assimilation using the observed refractivities directly as a constraint on the model forecast.

The first temperature inversion obtained from the GPS-MET experiment is shown in the figure. This sounding, obtained at 0744 GMT on 16 April 1995 for the location $2^{\circ} \mathrm{N}, 78^{\circ} \mathrm{W}$ is compared to the nearest radiosonde ( 4 hours later and $500 \mathrm{~km}$ away), shown by

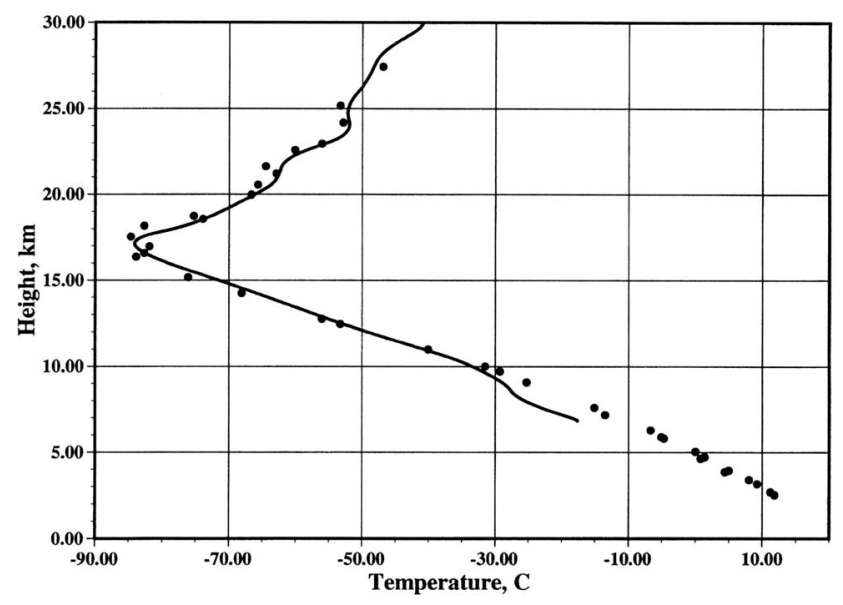

dots in the figure. This first sounding was obtained under the assumption of a dry atmosphere. The neglect of the water vapor effect, which is substantial in the lower troposphere, causes the cold bias in the GPS-MET sounding below about $8 \mathrm{~km}$ in the figure. Subsequent soundings show similar agreement with radiosonde data. These results will be summarized in a future article in the Bulletin.

UCAR's contract with OSC gives UCAR exclusive rights to the GPS-MET data for scientific use. In turn, UCAR is providing the data free of charge to scientists around the world via the World Wide Web site URL: http://pocc.gpsmet.ucar.edu. *Article contributed by Richard A. Anthes, University Corporation for
Atmospheric Research, Boulder, Colorado. 


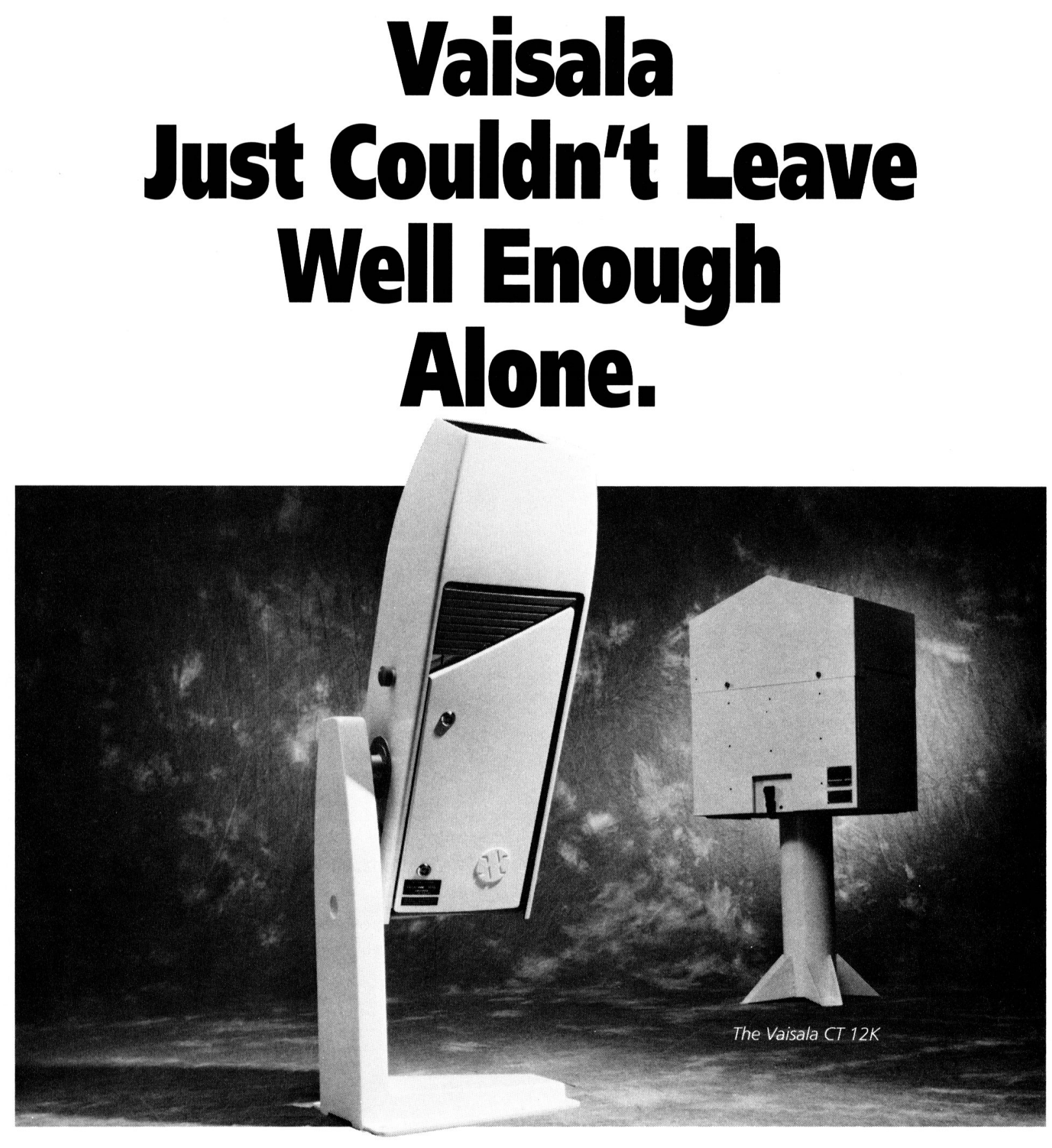

\section{The New Vaisala CT 25K Ceilometer}

We're never satisfied.

Our CT 12K ceilometer, approved for use in U.S. ASOS (NWS) and AWOS (FAA) weather stations, and by meteorological and military agencies worldwide, has long been recognized as the standard for cloud height measurement. Now, the new CT 25K, with its ability to detect cloud ceilings up to 25,000 feet, sets an even higher standard.

The CT 25K's unique optical design allows for accurate measurements to virtually ground level. Easily handled by one person, it offers door access for servicing in all kinds of weather. And its tiltable design lets you direct the beam in any direction. For more information, call or fax Vaisala today.

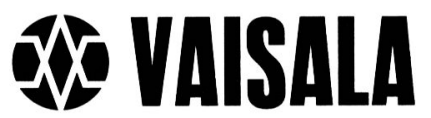

Measuring the Environment 100 Commerce Way, Woburn, MA 01801 Tel: (617) 933-4500 Fax: (617) 933-8029 